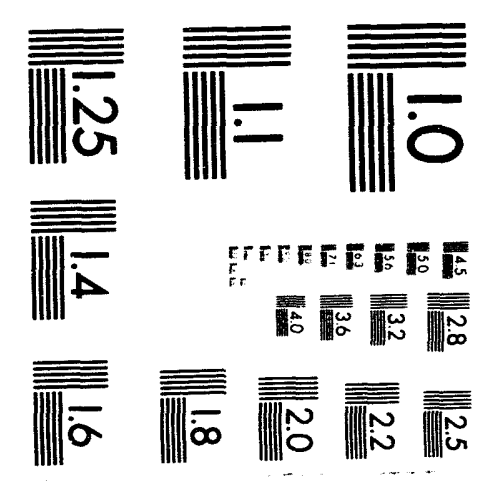




$$
\overrightarrow{\underline{a}}
$$




\section{Table of Contents}

Project Summary $\ldots \ldots \ldots \ldots \ldots \ldots \ldots \ldots \ldots \ldots \ldots \ldots \ldots \ldots$

Progress Report: Metallocarboxylate Chemistry, DOE, 4/89-9/91 . . . . . . 4

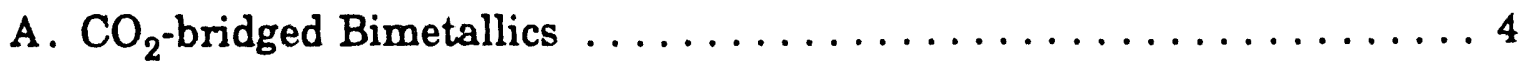

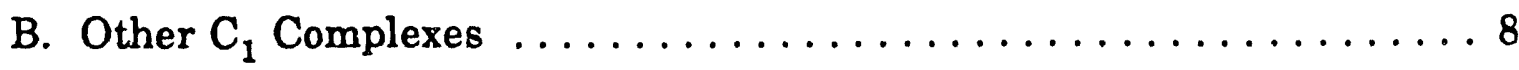

Publications Acknowledging DOE Support $\ldots \ldots \ldots \ldots \ldots \ldots \ldots \ldots$

Research Proposal: Metallocarboxylate Chemistry ............. 10

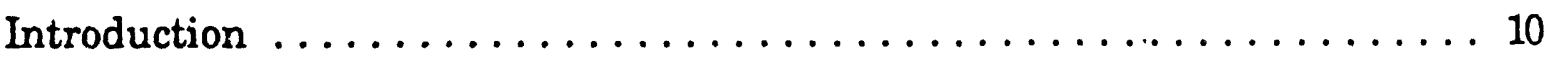

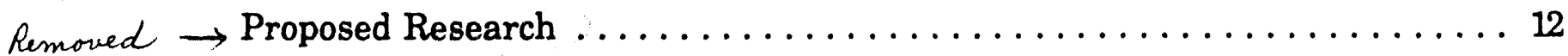

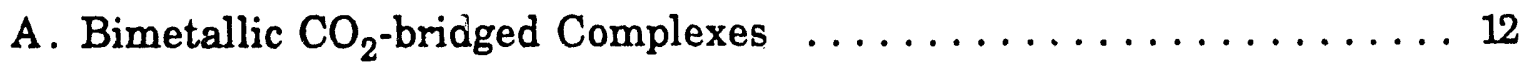

B. Bimetallic Complexes with Carboxyethylene (and related) Bridges .. 19

C. Bimetallic Carboxymethylene-bridged Complexes $\ldots \ldots \ldots \ldots \ldots 24$

D. Molecular Structure Collaboration $\ldots \ldots \ldots \ldots \ldots \ldots \ldots \ldots 26$

E. References .................................. 28

Biographical Sketch and Recent Publications $\ldots \ldots \ldots \ldots \ldots \ldots \ldots$

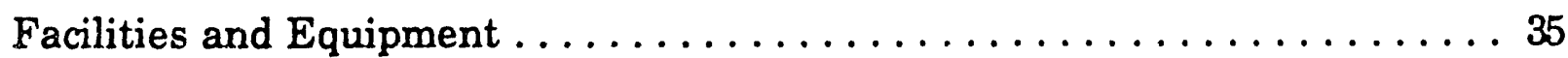

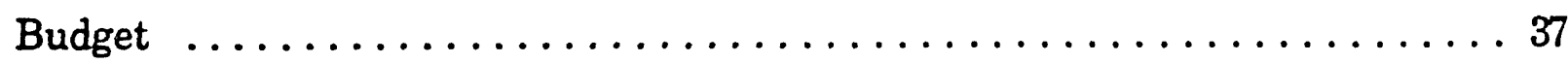

A. Year One Budget $\ldots \ldots \ldots \ldots \ldots \ldots \ldots \ldots \ldots \ldots \ldots \ldots \ldots \ldots \ldots$

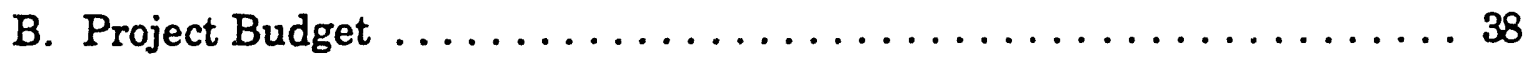

Current and Pending Support $\ldots \ldots \ldots \ldots \ldots \ldots \ldots \ldots \ldots \ldots \ldots$

Attachment: Selected ${ }^{13} \mathrm{C}$ NMR and DRIFTS Spectral Data for $\mu_{2}-\eta^{2}$ and $\mathrm{H}_{2}-\eta^{3} \mathrm{CO}_{2}$-bridged Complexes

\section{DISCLAIMER}

This report was prepared as an account of work sponsored by an agency of the United States Government. Neither the United States Government nor any agency thereof, nor any of their employees, makes any warranty, express or implied, or assumes any legal liability or responsibility for the accuracy, completeness, or usefulness of any information, apparatus, product, or process disclosed, or represents that its use would not infringe privately owned rights. Reference herein to any specific commercial product, process, or service by trade name, trademark, manufacturer, or otherwise does not necessarily constitute or imply its endorsement, recommendation, or favoring by the United States Government or any agency thereof. The views and opinions of authors expressed herein do not necessarily state or reflect those of the United States Government or any agency thereof.

\section{MASTER}

DISTRIBUTION OF THIS DOCUMENT IS UNLMMITED $97 \sigma^{\circ}$ 


\section{Project Summary: Metallocarborylate Chemistry}

This research proposal is focused on bimetallic compounds of late transition metals with carbon dioxide or $\mathrm{CO}_{2}$-containing bridging ligands. The compounds are models for catalytic intermediates in $\mathrm{CO}_{2}$ fixation processes leading to the synthesis of organic compounds. Preliminary work on two classes of $\mathrm{CO}_{2}$-bridged compounds and on carboxyethylene-bridged compounds is reported; the syntheses were initiated through reactions of a metallocarboxylate anion, $\mathrm{CpFe}(\mathrm{CO})\left(\mathrm{PPh}_{3}\right) \mathrm{COO}^{-} \mathrm{K}^{+}$. Initial work on the thermolysis of the $\mathrm{CO}_{2}-$ bridged compounds shows that the $\mu_{2}-\eta^{2}$ complexes lose $\mathrm{CO}$ and convert to $\mu_{2}-\eta^{3}-\mathrm{CO}_{2}$-bridged complexes and that some of the latter type can be further transformed, through additional $\mathrm{CO}$ loss, to bimetallic compounds containing an oxo ligand on one metal center. These reactions provide models for transformations of $\mathrm{CO}_{2}$ on metal surfaces. Further explorations of the chemistry of these compounds, and additional related ones, are proposed together with efforts to synthesize carboxydiene- and carboxyalkyne-bridged complexes. Also planned are methods to synthesize an additional class of bridged bimetallic compounds, ones with carboxymethylene bridges. The synthesis and characterization work will be followed by efforts to reduce and remove the bridged species, in useful form, as organic substrates. Wherever it is possible, we will obtain crystallographic data on these differing structural types to provide further insights into their reactivity. 
Brogress Report: "Metallocarboxylate Chemistry"

DE-FG05-86ER13538

April 1, 1989 - September 20, 1991

A. $\quad \mathrm{CO}_{2}$-Bridged Bimetallics

The goals of this research have been to establish synthetic routes to metallocarboxylates, MCOOM' $\left[\mathrm{M}=\mathrm{CpFe}(\mathrm{CO})\left(\mathrm{PPh}_{3}\right)\right.$ or $\mathrm{Cp} * \mathrm{Fe}(\mathrm{CO})\left(\mathrm{PPh}_{3}\right)$; $M^{\prime}=a l k a l i$, main or transition metal], to assess their stability and to explore their chemical reactions. Much of our efforts in this grant period have focused onthe metallocarboxylate anions. These alkali metal salts, as originally obtained, were hydrated; finding effective methods for converting these to the corresponding anhydrous salts was seen as crucial to their further use as synthons, especially for the preparation of bimetallic transition metal complexes with bridging $\mathrm{CO}_{2}$. We have settled on a procedure which utilizes potassium tri-sec-butyl borohydride to chemically dehydrate the hydrated salts. The dehydration procedure is tedious and must be conducted in a glovebox at low temperatures, but it is highly effective. Contrary to the dire predictions of one of the reviewers of the proposal preceding this work, the anhydrous salts are much more stable than their hydrated analogs (which suffer rapid hydrolysis in solution at ambient temperatures). All reactions of the metallocarboxylates, both hydrated and anhydrous, must be conducted in the glovebox as well as the preparation of all samples for spectral analysis. The glovebox has recently been fitted with a Neslab Cryocool unit to allow lower cold bath temperatures $\left(\right.$ to $\left.-100^{\circ} \mathrm{C}\right)$ to be attained for reactions.

Detailed analysis of the spectral characteristics (IR, DRIFTS, ${ }^{1} \mathrm{H}$ and ${ }^{13} \mathrm{C}$ NMR) of the hydrated and anhydrous salts, related esters and bimetallic tin derivatives of the metallocarboxylate anions were done to characterize the 
compounds and to identify those properties which could demonstrate the type of bonding of the carboxyl group in a particular class of compounds. DRIFTS data have been particularly helpful, clearly distinguishing $\eta^{2}$ - and $\eta^{3}$-complexes.

A lengthy study of the behavior of both hydrated and anhydrous salts with electrophiles (protonic acids and methylating agents primarily) was conducted in order to set the stage for the synthetic development of the metallocarboxylate salts. For the cyclopentadienyl systems with lithium and potassium counterions, (both hydrated and anhydrous) we determined that there is competitive cleavage of the $\mathrm{C}-\mathrm{O}$ and $\mathrm{O}-\mathrm{M}$ bonds of the carboxylate group by the electrophiles, with the more oxophilic lithium ion promoting $\mathrm{C}-\mathrm{O}$ bond cleavage. Comparison of the reactions of these potassium salts with their pentamethylcyclopentadienyl analogs showed that the $\mathrm{Cp}$ * ligand also promotes $\mathrm{C}-\mathrm{O}$ bond cleavage, especially when the electrophile is a protonic acid. Our results underscore the fundamental differences between metallocarboxylate anions and salts of organic carboxylic acids; the latter react with electrophiles at the O-M bond exclusively. It became clear from these studies that the anhydrous potassium salts would have the most utility in syntheses involving electrophilic reagents where preservation of the carboxyl group was desired. Although the anions are only weakly nucleophilic, they are active enough to use in reactions with strong electrophiles. Very importantly, they are quite stable to dissociative loss of $\mathrm{CO}_{2}$.

We have begun to explore the reactions of the metallocarboxylate anions with transition metal cations; our goals are to build $\mathrm{CO}_{2}$ ( or $\mathrm{CO}_{2}$-containing) bridged bimetallic compounds. Our target compounds are systems with two late transition metals. 
Using rhenium cations with $\mathrm{BF}_{4}^{-}$as the weakly coordinated anion, we have recently prepared $\mathrm{CO}_{2}$-bridged bimetallic complexes of the type $\mathrm{CpFe}(\mathrm{CO})\left(\mathrm{PPh}_{3}\right) \mathrm{CO}_{2} \operatorname{Re}(\mathrm{CO})_{4}(\mathrm{~L})\left[\mathrm{L}=\mathrm{CO}, \mathrm{PPh}_{3}\right.$ or $\left.\mathrm{P}(\mathrm{OPh})_{3}\right]$ and have begun to study their reactions. Spectral evidence supports the following course for thermolysis reactions:<smiles>[Y][R]([H])(C=O)OC(=O)[Te](=O)(C=O)c1ccccc1</smiles>

$\mathrm{L}=\mathrm{CO}, \mathrm{PPh}_{3}, \mathrm{P}\left(\mathrm{OPh}_{3}\right)$<smiles>CC=CC(C)C=C(C)C</smiles>

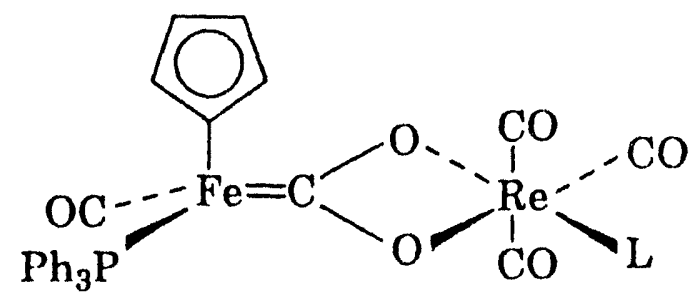<smiles>CC1(C=O)CC1</smiles>

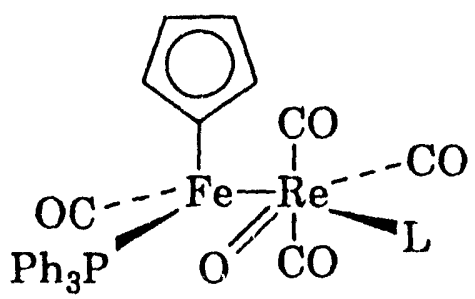

The complexes with $\mathrm{L}=\mathrm{CO}$ are extremely labile and we have not been able to obtain pure samples of any of them yet. The phosphite-substituted complexes are more amenable to purification and spectroscopically pure samples of all three have been obtained. The phosphine-substituted compounds are also relatively stable, but the carbene complex does not undergo the second transformation even under forcing thermal $\left(80^{\circ} \mathrm{C}\right.$, several days in the solid state) or photochemical conditions. The order of activity is thus $\mathrm{L}=\mathrm{CO}>\mathrm{P}(\mathrm{OPh})_{3}>\mathrm{PPh}_{3}$. DRIFTS and ${ }^{13} \mathrm{C}$ NMR spectral data clearly distinguish the $\mu_{2}-\eta^{2}$ and $\mu_{2}-\eta^{3}$-complexes (see attachment 1). The infrared spectra of the $\mu_{2}-\eta^{2}$-complexes show the carboxyl carbonyl at approximately $1500 \mathrm{~cm}^{-1}$ whereas the $\mu_{2}-\eta^{3}$-complexes show bands for 
a fully chelated carboxyl only. The carbon spectra, in the carbonyl and carboxyl areas, are quite distinct for the two classes of compounds also; especially significant is the shift (by approximately $30 \mathrm{ppm}$ ) downfield of the carboxyl carbon after the conversions of the $\mu_{2}-\eta^{2}$ - to the $\mu_{2}-\eta^{3}$-complexes. Changes in the ${ }^{13} \mathrm{C}$ NMR spectra, together with the observed strong absorption at approximately $950 \mathrm{~cm}^{-1}$ (for $\mathrm{Re}=0$ ) support the assignment of the oxo structure to the final thermolysis product $\left[\mathrm{L}=\mathrm{CO}, \mathrm{P}(\mathrm{OPh})_{3}\right.$ only $]$.

Both stages of the reaction sequence shown are unprecedented for carbon dioxide complexes. The first stage does have precedent with some related $\mathrm{CS}_{2}$ complexes; the diiron complex $\left[\mathrm{CpFe}(\mathrm{CO})_{2}\right]_{2} \mathrm{CS}_{2}$ was converted (in low yield) to the analogous carbene complex by photolysis.

Additionally, we have begun to probe the reactions of the iron metallocarboxylate anions with alkene-coordinated cations. The carboxylate adds to either of two ethylene-coordinated cations as shown below:

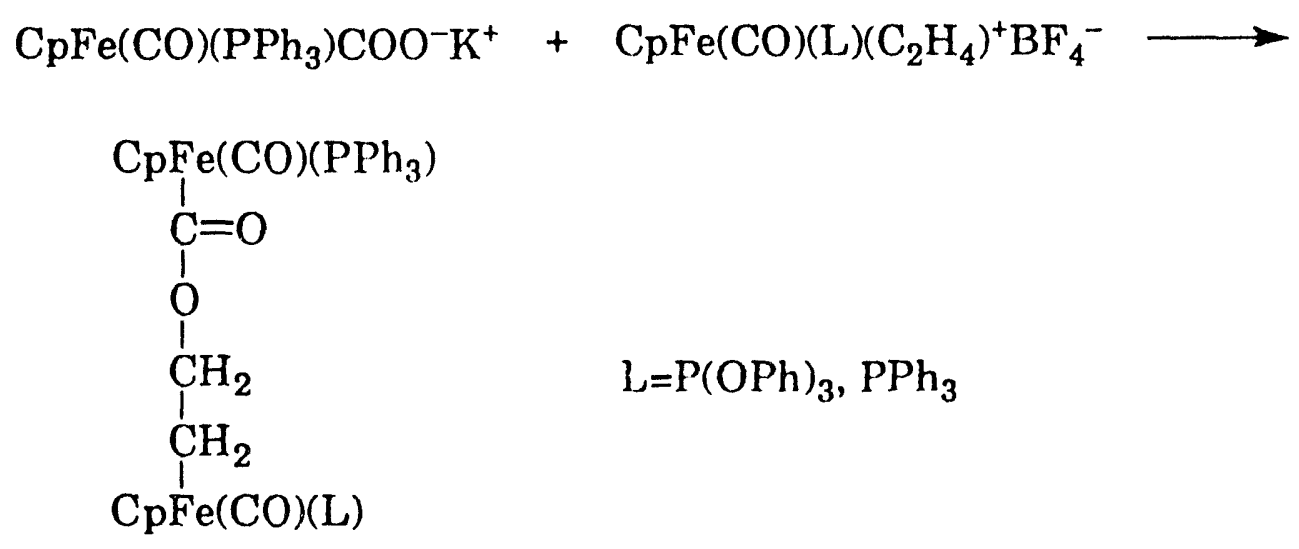

The compounds can be obtained readily and have been characterized by spectral methods and by elemental analysis. This type of coupling of coordinated carbon dioxide to metal-bound ethylene has not been observed previously; reactions of $\mathrm{CO}_{2}$ with ethylene and other alkenes have involved $\mathrm{C}-\mathrm{C}$ bond formation. The type of reaction which we have observed generates compounds which would model 
intermediates in processes leading to formate esters and other oxygenates. The compounds shown above are cleaved by excess $\mathrm{HBF}_{4}$ and yield the original ethylene-coordinated cations together with the metal carbonyl cation from the other fragment. Solvolysis of the bimetallic compounds in methanol leads to the carboxylate methyl ester and the corresponding methoxyethyl complex, $\mathrm{CpFe}(\mathrm{CO})(\mathrm{L})\left(\mathrm{CH}_{2} \mathrm{CH}_{2} \mathrm{OCH}_{3}\right)$. The route by which the latter compound is formed is under investigation.

B. Other $\mathrm{C}_{1}$ Complexes

As indicated in the titles of publications acknowledging DOE support during this period (attached), other aspects of transition metal- $\mathrm{C}_{1}$ chemistry have been under investigation in my laboratory for the past several years; these efforts have been partially supported by DOE. While some of them may not seem to be directly related to metallocarboxylate chemistry, the research has broadened our understanding of the chemistry of $\mathrm{C}_{1}$ complexes through studies of formyl, halomethyl, alkoxymethyl, aminomethyl, carbene and ylide complexes and metallacycles derived from the formyl complexes. The knowledge and experience gained by doing this work will be very valuable as we try to develop the metallocarboxylate chemistry further. Also, the reaction chemistry of the halomethyl complexes bears directly on the current proposal.

Funds are now available from the National Science Foundation to support extensions of the metal-formyl chemistry. This grant will focus on several classes of bimetallic compounds with oxygenate bridging groups which are possible models for intermediates in Fischer-Tropsch processes leading to ethylene glycol, glycol aldehyde, etc. The pending NSF/EPSCoR proposal is in the same general area. In neither case would the work overlap with the work described in the present proposal. 


\section{Publications Acknowledging DOE Support}

April, 1989 - September, 1991

a) Published

Synthesis of Halomethyl Complexes from Metal Formyls, Dorothy H. Gibson, Santosh K. Mandal, Kathryn Owens, William E. Sattich and Jaime O. Franco, Qrganometallics, 8, 1114 (1989).

Synthesis and Characterization of Manganese and Rhenium Metallacycles, Dorothy H. Gibson, Santosh K. Mandal, Kathryn Owens and John F. Richardson, Organometallics, 9, 424 (1990).

Synthesis and Characterization of Sec ondary Carbene Complexes of Manganese and Rhenium, Dorothy H. Gibson, Santosh K. Mandal, Kathryn Owens and John F. Richardson, Organometallics, 9, 1936 (1990).

Synthesis and Characterization of Iron Metallocarboxylates, Dorothy H. Gibson, Tek-Sing Ong and Ming Ye, Organometallics, 10, 1811 (1991).

1-Carbonyl- $\eta^{5}$-cyclopentadienyl-2,2,2-triphenyl-1-triphenylphosphine- $\mu$ carboxylate-1KC:2KO:2KO'-irontin, Dorothy H. Gibson, John F. Richardson and Tek-Sing Ong, Acta Cryst. C, C47, 259 (1991).

Synthesis of Alkoxymethyl Complexes from Metal Formyls, Dorothy H. Gibson, Kathryn Owens, Santosh K. Mandal, William E. Sattich and Jaime O. Franco, Organometallics, 10, 1203 (1991).

Synthesis and Characterization of Aminomethyl Complexes of Rhenium, Dorothy H. Gibson and Kathryn Owens, Organometallics, 10, 1216 (1991).

\section{b) Accepted for Publication}

$\eta^{5}$-Cyclopentadienyl-dicarbonyl-triphenylphosphite triphenylphosphoniummethylide molybdenum p-toluene-sulfonate, Dorothy $\mathrm{H}$. Gibson, John F. Richardson and Jaime O. Franco, Acta Cryst., in press. 

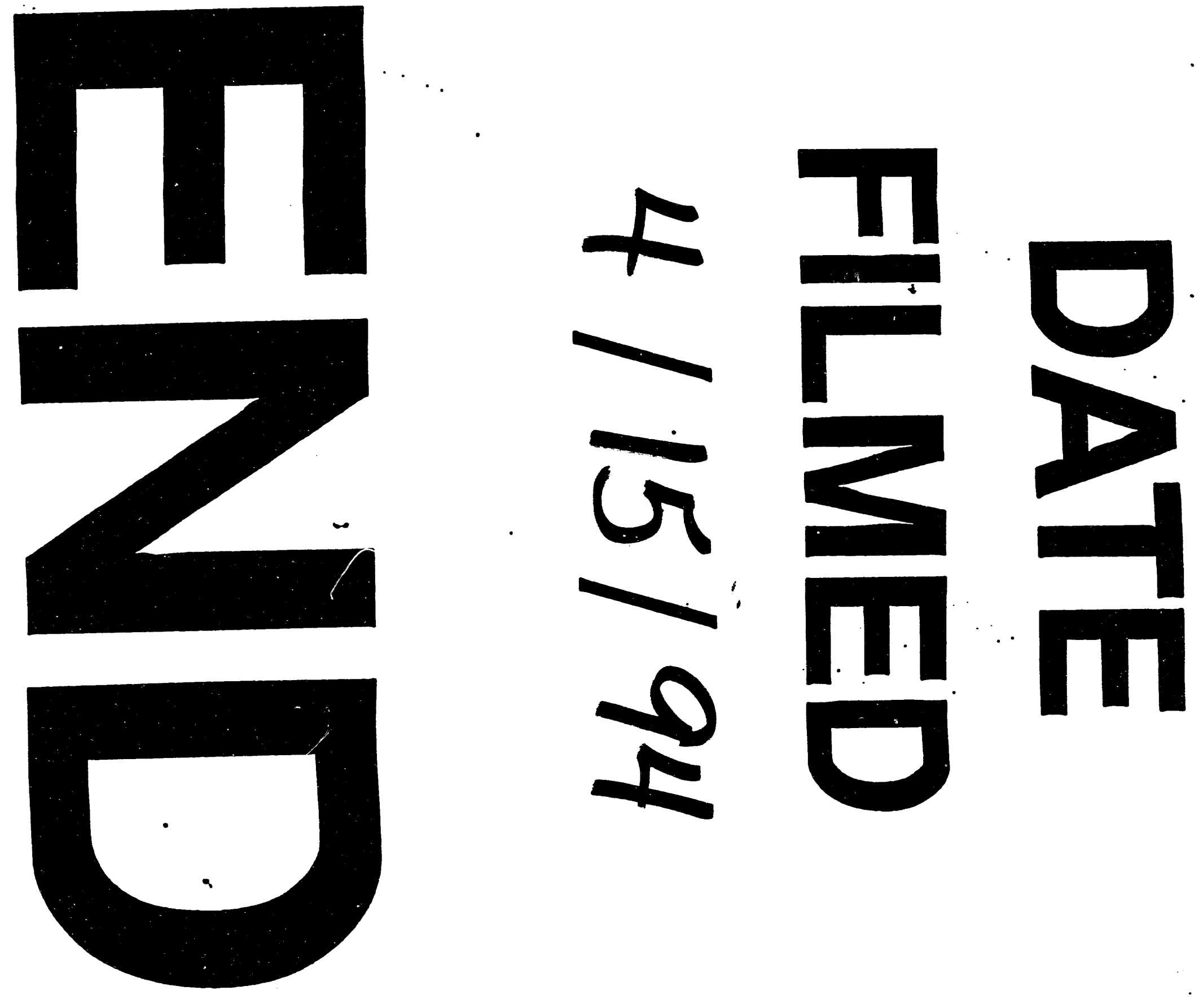
